\title{
A Possible Procedure to Prepare Mono Fatty Acid-Enriched Plasma Membrane in Chicken Hepatocytes
}

\author{
Toshihiro TAKAHASHI, Kan SATO and Yukio AKIBA \\ Department of Animal Science, Faculty of Agriculture, Tohoku University, \\ Aoba-ku, Sendai-shi 981-8555, Japan \\ (Received December 16, 1998 ; Accepted February 26, 1999)
}

\begin{abstract}
In a viewpoint to explore an experimental model to study the regulatory mechanism of hepatic lipogenesis by $n-3$ fatty acids on hepatic lipogenesis, three experiments were undertaken to prepare mono fatty acid-enriched plasma membrane phospholipid in chicken hepatocytes. Incubation with $500 \mu \mathrm{M} \alpha$-linolenic acid for $24 \mathrm{~h}$ in the primary culture of chicken hepatocytes significantly increased $\alpha$-linolenic acid content and decreased oleic acid content in the plasma membrane phospholipid. In a same fashion, addition of linoleic acid or oleic acid to the media resulted in the higher proportion of the corresponding fatty acid in the plasma membrane. In the subsequent incubation in a fatty acid-free media of $\alpha$-linolenic acid-enriched cells, $\alpha$-linolenic acid content decreased gradually with a half life of $24 \mathrm{~h}$. Our results suggest that fatty acid supplementation to the culture medium modifies the fatty acid composition of plasma membrane phospholipid of chicken hepatocytes. The present chicken primary culture system may be applicable for investigation of regulatory mechanism of lipid metabolism.
\end{abstract}

Animal Science Journal 70 (3) : 118-123, 1999

Key words : Lipogenesis, Membrane phospholipid, Hepatocyte, Fatty acid ( $n-3$ and $n-6)$, Chicken

Dietary fat containing $n-3$ fatty acids suppressed hepatic fatty acid synthase activity and lowered liver triacylglycerol contents in chickens ${ }^{3)}$. Dietary $n-6$ and $n-3$ polyunsaturated fatty acids (PUFA) have been shown to reduce fatty acid synthesis and triacylglycerol contents in rat liver ${ }^{20)}$. The regulatory mechanisms of lipogenesis by $n-3$ fatty acids in chickens and mammals have been of considerable interest in recent years. Schwartz and Abraham ${ }^{12)}$ showed that a decrease of hepatic fatty acid synthase activity by dietary PUFAs was a resultant of a decrease in the enzyme content in mice. Cheema et al. ${ }^{3)}$ reported that the PUFAs directly regulated gene expression of mRNA of fatty acid synthase in mice. On the other hand, Strum-Odin et al. ${ }^{16)}$ suggested that the decrease of triacylglycerol synthesis by dietary $n-3$ PUFA was an indirect consequence of $n-3$ fatty acid enrichment of hepatic membrane phospholipids in rats. Iritani and Fukuda ${ }^{9)}$ reported that insulin binding to receptors in rat hepatic membrane was modified by dietary fat sources. These observations suggest that PUFA regulates hepatic lipogenesis through either its direct effects on the lipogenic enzyme and/or indirect modification of the hepatic membrane function.

For the verification of the indirect effects of PUFA as well as $n-3$ fatty acid on lipogenesis in hepatocytes, it seems essential to provide the hepatocyte plasma membrane phospholipid enriched with various fatty acids which are different in the chain length and saturation. Strum-Odin et al. ${ }^{16)}$ have reported that enrichment with the specific fatty acid in the incubation media affects fatty acid composition of microsomal membrane in rat hepatocytes. There is, however, less information available on the modification of plasma membrane fatty acid profile in primary hepatocytes culture of chickens and mammals.

Corresponding: Yukio AKIBA (fax : +81 (0) 22-717-8691, e-mail : akiba@bios.tohoku.ac.jp)

Anim. Sci. J. $70(3): 118-123,1999$ 
The present work was conducted to prepare mono fatty acid-enriched plasma membrane in chicken hepatocyte by supplementing incubation media with $18: 3(n-3)$. In addition, the possibility to prepare mono fatty acid-enriched hepatic plasma membrane was studied by incubating chicken hepatocytes with $18: 1(n-9)$ and $18: 2(n-6)$.

\section{Materials and Methods}

\section{Animals and diets}

Male broiler chickens (Ross strain) with body weight ranging from 1,000 to $1,200 \mathrm{~g}$ were provided. The chickens were fed ad libitum on a commercial bloiler starter diet (crude protein $22 \%$, metabolizable energy $3,200 \mathrm{kcal} / \mathrm{kg}$ ) and housed in wire cages.

\section{Chemicals}

Fatty acid sodium salts were obtained from Nacalai Tesque Inc. (Kyoto, Japan). Glucagon and essentially fatty acid-free bovine serum albumin were purchased from SIGMA (St. Louis, MO, USA). Basal Medium Eagle and antibiotics were obtained from GIBCO BRL (Rockville, MD, USA). Other regents were obtained from Wako Pure Chemical Co. (Osaka, Japan). Chicken serum was prepared from 3-4 weeks old male broiler chickens.

\section{Primary culture of Chicken hepatocytes}

Chicken liver cells were prepared and maintained in monolayer culture essentially as described by Seglen ${ }^{13)}$ and Tarlow et al. ${ }^{18)}$. Hepatocytes were isolated from four week-old male broiler chickens starved for $12 \mathrm{~h}$. Livers were perfused at a rate of $23 \mathrm{~m} l / \mathrm{min}$ with sterile Hank's Balanced Salt Solution (HBSS) containing $0.5 \mathrm{mM}$ EGTA and $10 \mathrm{mM}$ HEPES at $37^{\circ} \mathrm{C}$ for 5 $10 \mathrm{~min}$, followed by perfusion at the same rate with HBSS containing $0.05 \%$ collagenase for additional 7 $15 \mathrm{~min}$. The digested liver was removed, minced, washed and filtered through $25 \mu \mathrm{m}$ stainless stecl mesh. The hepatocytes with more than $90 \%$ of viability which were verified by Trypan blue exclusion test were used for subsequent plating. The hepatocytes were plated $\left(2 \times 10^{7}\right.$ cells $/ \phi 60 \mathrm{~mm}$ collagen coated dish) in incubation medium (Basal Medium Eagle supplemented with essential amino acids), containing $75 \mathrm{U} / \mathrm{m} l$ penicillin and $75 \mu \mathrm{g} / \mathrm{m} l$ streptomycin, $1 \mu \mathrm{g} / \mathrm{m} l$ insulin, $1 \mu \mathrm{g} / \mathrm{m} l$ glucagon and
$0.5 \%$ chicken serum and incubated for $4 \mathrm{~h}$ at $37^{\circ} \mathrm{C}$ in $5 \% \mathrm{CO}_{2}$ as a gas phase. The medium was subsequently replaced with fresh incubation medium and the hepatocytes were incubated for another $20 \mathrm{~h}$ in order to achieve the hepatocyte monolayer.

After $20 \mathrm{~h}$ incubation (attachment phase), the cultures were changed to experimental media containing $0.1 \mu \mathrm{g} / \mathrm{m} /$ insulin, $1 / \mu \mathrm{g} / \mathrm{m} /$ glucagon, $0.5 \%$ serum and $500 \mu \mathrm{M}$ of sodium salts of fatty acid with essentially fatty acid-free BSA (molar ratio of $3.6: 1$ ). The medium was changed at $24 \mathrm{~h}$ intervals. At the end of incubation, the cells were washed 2 times with PBS and were dissociated from culture plates by treatment with $0.1 \%$ trypsin.

\section{Experiments 1, 2 and 3}

To manipulate the fatty acid composition of plasma membrane phospholipid in chicken hepatocyte primary culture, three experiments were conducted.

In experiment 1 , chicken hepatocytes were maintained in culture for $24 \mathrm{~h}$ with medium containing 18 : $3(n-3)$ for the preparation of $n-3$ fatty acid rich plasma membrane in chicken hepatocytes.

In experiment 2 , in vitro incubations were undertaken with $18: 3(n-3), 18: 2(n-6)$ and $18: 1(n-9)$ in order to prepare plasma membrane rich in corresponding fatty acid in chicken hepatocytes.

In experiment 3 , to monitor the transitional changes of specific fatty acid content of $18: 3(n-3)$-enriched plasma membrane, chicken hepatocytes enriched by $24 \mathrm{~h}$ incubation with $18: 3(n-3)$ were cultured with a serum-, hormone- and fatty acid-free medium for another $48 \mathrm{~h}$.

\section{Preparation of plasma membrane}

The hepatocytes were sonicated by sonic homogenizer (SONIFIER Cell Disruptor 185, Branson U1trasonics Co., CT, USA) and the plasma membrane fraction was obtained by the method of Belsham et al. ${ }^{2)}$. All preparation procedure were executed below $4^{\circ} \mathrm{C}$.

Lipid extraction from hepatocytes and plasma membrane fraction

Total lipids of plasma membrane fraction in hepatocytes were extracted by the method of Folch et al. ${ }^{7)}$. Phospholipid fractions were isolated by silica column (Sep-Pak Plus Silica Cartridges, Waters Co., 
MA, USA) according to the method of Fleischer et al. ${ }^{6)}$ and quantified by the method of Sipos and Ackman $^{14)}$ using TLC-FID equipment (IATROSCAN TH-10, IATRON LABORATORIES, INC., Tokyo, Japan) connected to an electronic integrator.

\section{Fatty acid analysis}

Fatty acid methyl esters were prepared using 5\% $\mathrm{HCl}$-methanol. The fatty acid methyl esters were separated by gas-liquid chromatography (HP 6890 System, Hewlett-Packard Co., DE, USA) using $60 \mathrm{~m}$ capillary column (HP INNOWAX, Hewlett-Packard Co., DE, USA) and a temperature program of 180 $230^{\circ} \mathrm{C}$, with a $3^{\circ} \mathrm{C}$ rise per min.

\section{Statistical analysis}

Statistical analysis was carried out using the $\mathrm{SAS}^{15)}$. The effects of fatty acid supplement and time in culture on fatty acid compositions were analyzed by ANOVA using a general linear models procedure followed by Duncan's multiple range test $(\mathrm{P}<0.05)$.

\section{Results}

Experiment 1: Plasma membrane phospholipids in chicken hepatocytes were characterized by about $20 \%$ each of $16: 0,18: 0$ and $18: 1(n-9)$ and about $10 \%$ each of $18: 2(n-6), 20: 4(n-6)$ and $22: 6(n-3)$ as shown in the fatty acids profile of the initial cells
(Table 1). No significant changes of PUFA contents in plasma membrane phospholipids were observed after $24 \mathrm{~h}$ incubation in the fatty acid-free medium (initial cell vs. none). Supplementation of $500 \mu \mathrm{M}$ $18: 3(n-3)$ increased extensively the $18: 3(n-3)$ content of the plasma membrane phospholipids but decreased the $16: 0$ and $18: 1(n-9)$ contents. However, $18: 3(n-6)$ and $20: 5(n-3)$ contents were not significantly changed by the supplementation of $18: 3$ $(n-3)$.

Experiment 2 : Table 2 shows the characteristic profile of fatty acid composition of the hepatocyte phospholipid plasma membrane incubated for $24 \mathrm{~h}$ in media containing each of $18: 1(n-9), 18: 2(n-6)$ and $18: 3(n-3)$. Supplementation of mono fatty acid significantly elevated respective acid content in the plasma membrane without influencing $18: 3(n-6)$ and $20: 5(n-3)$ contents. The three fold increase in $18: 2(n-6)$ content in the hepatocytes of the $18: 2$ ( $n-6)$ supplemented cultures were compensated by the decrease of $18: 1(n-9)$ content. In the same fashion, high $18: 3(n-3)$ content $(17 \%)$ in the $18: 3(n-$ $3)$-supplemented cultures is mirrored by low $18: 1(n$ 9) content.

Experiment 3 : Incubation of $18: 3(n-3)$-enriched ( $15 \%$ of total fatty acids) hepatocytes in the fatty

Table 1. Changes of fatty acid composition (wt $\%$ ) of plasma membrane phospholipid from hepatocyte monolayers

\begin{tabular}{cccc}
\hline & & \multicolumn{2}{c}{ After $24 \mathrm{~h}$ incubation with } \\
\cline { 3 - 4 } Fatty acid & Before incubation & None & $18: 3(n \cdot 3)$ \\
\hline $16: 0$ & $19.2 \pm 0.7^{\mathrm{a}}$ & $20.9 \pm 0.8^{\mathrm{a}}$ & $15.3 \pm 1.7^{\mathrm{b}}$ \\
$16: 1(n-7)$ & $1.1 \pm 1.0^{\mathrm{b}}$ & $2.8 \pm 0.2^{\mathrm{a}}$ & $0.7 \pm 0.1^{\mathrm{b}}$ \\
$18: 0$ & $22.6 \pm 1.2^{\mathrm{a}}$ & $19.8 \pm 1.8^{\mathrm{b}}$ & $22.8 \pm 0.9^{\mathrm{a}}$ \\
$18: 1(n-9)$ & $17.6 \pm 3.0^{\mathrm{b}}$ & $23.2 \pm 1.9^{\mathrm{a}}$ & $11.1 \pm 0.5^{\mathrm{c}}$ \\
$18: 2(n-6)$ & $10.0 \pm 0.8^{\mathrm{b}}$ & $9.1 \pm 0.4^{\mathrm{b}}$ & $14.0 \pm 1.0^{\mathrm{a}}$ \\
$18: 3(n-6)$ & $0.5 \pm 0.5$ & $0.6 \pm 0.2^{2}$ & $0.7 \pm 0.2$ \\
$18: 3(n-3)$ & $0.1 \pm 0.2^{\mathrm{b}}$ & $0.6 \pm 0.6^{\mathrm{b}}$ & $15.2 \pm 1.4^{\mathrm{a}}$ \\
$20: 4(n-6)$ & $11.5 \pm 1.1^{\mathrm{a}}$ & $11.6 \pm 0.6^{\mathrm{a}}$ & $9.1 \pm 1.5^{\mathrm{b}}$ \\
$20: 5(n-3)$ & $3.8 \pm 2.1$ & $2.7 \pm 1.5$ & $5.6 \pm 4.5$ \\
$22: 6(n-3)$ & $13.4 \pm 3.6^{\mathrm{a}}$ & $8.8 \pm 2.1^{\mathrm{ab}}$ & $5.7 \pm 2.2^{\mathrm{b}}$ \\
\hline
\end{tabular}

Values are expressed as mean proportion and SD of total fatty acids $(n=3)$.

$a, b, c$ Values in a row with different superscripts are significantly different,

$\mathbf{P}<0.05$. 
Plasma Membrane in Chicken Hepatocytes

Table 2. Changes of fatty acid composition (wt \%) in plasma membrane phospholipid from hepatocytes incubated with various mono fatty acid

\begin{tabular}{lccccc}
\hline & & \multicolumn{4}{c}{ After $24 \mathrm{~h}$ incubation with } \\
\cline { 3 - 6 } Fatty acid & $\begin{array}{c}\text { Before } \\
\text { incubation }\end{array}$ & None & $18: 1(n-9)$ & $18: 2(n-6)$ & $18: 3(n-3)$ \\
\hline $16: 0$ & $20.1 \pm 1.0^{\mathrm{a}}$ & $19.6 \pm 1.8^{\mathrm{a}}$ & $16.0 \pm 0.4^{\mathrm{bc}}$ & $16.7 \pm 0.6^{\mathrm{b}}$ & $14.3 \pm 0.5^{\mathrm{c}}$ \\
$16: 1(n-7)$ & $1.5 \pm 0.1^{\mathrm{c}}$ & $2.4 \pm 0.2^{\mathrm{a}}$ & $2.0 \pm 0.3^{\mathrm{b}}$ & $0.8 \pm 0.1^{\mathrm{d}}$ & $0.9 \pm 0.2^{\mathrm{d}}$ \\
$18: 0$ & $23.9 \pm 2.1^{\mathrm{ab}}$ & $25.5 \pm 0.7^{\mathrm{a}}$ & $22.5 \pm 0.9^{\mathrm{b}}$ & $25.6 \pm 0.9^{\mathrm{a}}$ & $25.5 \pm 0.4^{\mathrm{a}}$ \\
$18: 1(n-9)$ & $15.8 \pm 1.2^{\mathrm{c}}$ & $20.4 \pm 1.5^{\mathrm{b}}$ & $28.4 \pm 2.0^{\mathrm{a}}$ & $6.7 \pm 1.2^{\mathrm{e}}$ & $10.0 \pm 0.4^{\mathrm{d}}$ \\
$18: 2(n-6)$ & $10.6 \pm 0.2^{\mathrm{c}}$ & $9.1 \pm 0.5^{\mathrm{c}}$ & $10.7 \pm 0.7^{\mathrm{c}}$ & $33.6 \pm 1.8^{\mathrm{a}}$ & $14.0 \pm 0.2^{\mathrm{b}}$ \\
$18: 3(n-6)$ & $0.6 \pm 0.3$ & $1.4 \pm 1.3$ & $0.4 \pm 0.3$ & $0.2 \pm 0.2$ & $0.6 \pm 0.3$ \\
$18: 3(n-3)$ & $0.2 \pm 0.3^{\mathrm{b}}$ & $0.6 \pm 0.5^{\mathrm{b}}$ & $0.6 \pm 0.3^{\mathrm{b}}$ & $\mathrm{ND}$ & $16.9 \pm 0.7^{\mathrm{a}}$ \\
$20: 4(n-6)$ & $10.6 \pm 0.2^{\mathrm{a}}$ & $8.8 \pm 0.2^{\mathrm{b}}$ & $8.5 \pm 0.6^{\mathrm{b}}$ & $8.1 \pm 1.2^{\mathrm{b}}$ & $6.5 \pm 0.3^{\mathrm{c}}$ \\
$20: 5(n-3)$ & $2.5 \pm 0.8$ & $1.6 \pm 0.1$ & $1.7 \pm 0.7$ & $1.6 \pm 0.9$ & $2.7 \pm 0.5$ \\
$22: 6(n-3)$ & $14.4 \pm 1.3^{\mathrm{a}}$ & $10.8 \pm 0.5^{\mathrm{b}}$ & $9.4 \pm 1.5^{\mathrm{bc}}$ & $6.7 \pm 0.2^{\mathrm{d}}$ & $8.7 \pm 0.8^{\mathrm{c}}$
\end{tabular}

Values are expressed as mean proportion and SD of total fatty acids $(\mathrm{n}=3)$.

$\mathbf{a}, \mathbf{b}, \mathrm{c}, \mathrm{d}, \mathrm{e}$ Values in a row with different superscripts are significantly different, $\mathbf{P}<0.05$.

ND : not detected.

acid-free medium resulted in significant decrease, $50 \%$ for every $24 \mathrm{~h}$ till $48 \mathrm{~h}$ period (Table 3 ). Whilst the content of $18: 3(n-3)$ decreased, gradual increases were observed in $16: 0$ and $18: 1(n-9)$ in the cultures with no $18: 3(n-3)$. In the PUFA contents, small decreases in $18: 2(n-6)$ and $22: 6(n-3)$ were observed after $48 \mathrm{~h}$ incubation with no $18: 3(n-3)$. Minor differences were demonstrated in fatty acid profile of the hepatocyte plasma membrane between pre- and post- incubation with medium containing no fatty acids.

\section{Discussion}

It is well established that dietary fatty acid composition influences the fatty acid composition of plasma membrane in liver and adipose tissue of rats ${ }^{5,8,17,19)}$. In primary cell cultures, Strum-Odin et al. ${ }^{16)}$ showed that supplementation of specific fatty acid to the culture media caused an enrichment of the corresponding fatty acid in microsomal membrane of rat hepatocytes. However, little is known as to whether plasma membrane fatty acid composition is modified by supplementation of specific fatty acid in the primary culture of hepatocytes in either rats or chickens, though it has been reported that in HepG2 cells, physico-chemical properties of plasma membrane were essentially similar to those of microsomal membrane ${ }^{10)}$. Our data demonstrated that the hepatocyte plasma membrane with mono fatty acidenriched phospholipid moiety could be prepared by 24 $h$ incubation of chicken primary hepatocytes with 500 $\mu \mathrm{M}$ mono fatty acid such as $18: 1(n-9), 18: 2(n-6)$ and $18: 3(n-3)$. Among the mono fatty acidenriched hepatocytes, the extent of the enrichment in the $18: 1(n-9)$-enriched cells was less pronounced than those in the $18: 2(n-6)$ and $18: 3(n-3)$ cells probably because of the relatively high $18: 1(n-9)$ content in the control cells. However, $18: 3(n-3)$ content in the 18:3 (n-3)-enriched hepatocytes declined at a rate of $50 \%$ per every $24 \mathrm{~h}$ in the subsequent incubation with no fatty acid. It is suggested, therefore, that an appreciable enrichment of specific fatty acid in the hepatocyte plasma membrane is sustained for at least $24 \mathrm{~h}$ when the cells were subsequently incubated in a medium with no fatty acids in the present culture system. It is likely that turn over rate of fatty acid in the plasma membrane phospholipid is relatively high.

Physico-chemical changes of plasma membrane, changes in the membrane function and events in the 
TAKAHASHI, SATO and AKIBA

Table 3. Changes of fatty acid composition (wt \%) in plasma membrane phospholipid of $18: 3(n-3)$-enriched hepatocytes after incubation with no fatty acids

\begin{tabular}{|c|c|c|c|}
\hline Fatty acid & $\begin{array}{l}\text { Culture time in fatty } \\
\text { acid-free medium }\end{array}$ & Control cells & $\begin{array}{l}18: 3(n-3)- \\
\text { enriched cells }\end{array}$ \\
\hline \multirow{3}{*}{$16: 0$} & Oh & $21.8 \pm 0.7^{b}$ & $15.9 \pm 0.4^{c}$ \\
\hline & $24 \mathrm{~h}$ & - & $17.1 \pm 0.3^{c}$ \\
\hline & $48 \mathrm{~h}$ & $23.9 \pm 1.0^{a}$ & $21.8 \pm 1.1^{\mathrm{b}}$ \\
\hline \multirow[t]{3}{*}{$16: 1(n-7)$} & $\mathrm{Oh}$ & $2.3 \pm 0.0^{a}$ & $0.6 \pm 0.1^{\mathrm{b}}$ \\
\hline & $24 \mathrm{~h}$ & - & $0.8 \pm 0.0^{b}$ \\
\hline & $48 \mathrm{~h}$ & $2.7 \pm 0.2^{\mathrm{a}}$ & $2.4 \pm 0.7^{\mathrm{a}}$ \\
\hline \multirow[t]{3}{*}{$18: 0$} & $0 \mathrm{~h}$ & $29.1 \pm 0.4^{c}$ & $27.8 \pm 0.3^{\mathrm{d}}$ \\
\hline & $24 \mathrm{~h}$ & - & $31.9 \pm 0.2^{a}$ \\
\hline & $48 \mathrm{~h}$ & $30.5 \pm 1.3^{b}$ & $29.4 \pm 0.5^{b c}$ \\
\hline \multirow[t]{3}{*}{$18: 1(n-9)$} & $\mathrm{Oh}$ & $18.0 \pm 0.5^{b}$ & $8.5 \pm 0.1^{d}$ \\
\hline & $24 \mathrm{~h}$ & - & $7.9 \pm 0.1^{\mathrm{d}}$ \\
\hline & $48 \mathrm{~h}$ & $19.2 \pm 0.9^{a}$ & $12.1 \pm 0.4^{c}$ \\
\hline \multirow[t]{3}{*}{$18: 2(n-6)$} & $\mathrm{Oh}$ & $9.9 \pm 0.2^{d}$ & $16.1 \pm 0.4^{b}$ \\
\hline & $24 \mathrm{~h}$ & - & $17.9 \pm 0.3^{\mathrm{a}}$ \\
\hline & $48 \mathrm{~h}$ & $7.5 \pm 0.6^{\mathrm{e}}$ & $14.9 \pm 0.5^{c}$ \\
\hline \multirow[t]{3}{*}{$18: 3(n-6)$} & $\mathrm{Oh}$ & $0.1 \pm 0.0$ & ND \\
\hline & $24 \mathrm{~h}$ & - & ND \\
\hline & $48 \mathrm{~h}$ & $0.1 \pm 0.2$ & $0.1 \pm 0.1$ \\
\hline \multirow[t]{3}{*}{$18: 3(n-3)$} & $\mathrm{Oh}$ & ND & $15.0 \pm 0.7^{a}$ \\
\hline & $24 \mathrm{~h}$ & - & $8.4 \pm 0.3^{b}$ \\
\hline & $48 \mathrm{~h}$ & ND & $4.1 \pm 0.1^{c}$ \\
\hline \multirow[t]{3}{*}{$20: 4(n-6)$} & $\mathrm{Oh}$ & $10.0 \pm 0.2^{a}$ & $8.8 \pm 0.3^{b}$ \\
\hline & $24 \mathrm{~h}$ & - & $9.1 \pm 0.3^{\mathrm{ab}}$ \\
\hline & $48 \mathrm{~h}$ & $9.0 \pm 1.0^{\mathrm{ab}}$ & $8.6 \pm 0.5^{b}$ \\
\hline \multirow[t]{3}{*}{$20: 5(n-3)$} & $\mathrm{Oh}$ & $0.4 \pm 0.0^{\mathrm{b}}$ & $0.3 \pm 0.0^{\mathrm{b}}$ \\
\hline & $24 \mathrm{~h}$ & - & $0.3 \pm 0.0^{\mathrm{b}}$ \\
\hline & $48 \mathrm{~h}$ & $0.6 \pm 0.2^{\mathrm{a}}$ & $0.2 \pm 0.1^{b}$ \\
\hline \multirow[t]{3}{*}{$22: 6(n-3)$} & $\mathrm{Oh}$ & $8.4 \pm 0.2^{a}$ & $7.1 \pm 0.4^{\mathrm{b}}$ \\
\hline & $24 \mathrm{~h}$ & - & $6.6 \pm 0.3^{b c}$ \\
\hline & $48 \mathrm{~h}$ & $6.4 \pm 0.4^{c}$ & $6.3 \pm 0.4^{c}$ \\
\hline
\end{tabular}

Values are expressed as mean proportion and SD of total fatty acids $(n=3)$.

${ }^{a, b}, c, d, e$ Values with different superscripts for each fatty acid are significantly different, $\mathbf{P}<0.05$.

ND : not detected.

subsequent signal transduction might be an area of interest in order to understand the mechanism of lipid metabolism regulation of hepatic tissues. Clamp et $a l .{ }^{4)}$ noted that diet-induced changes in the fatty acid composition of hepatic plasma membrane influenced the proportion of lipid free to diffuse in rat plasma membrane. Morson and Clandinin ${ }^{11)}$ observed that dietary linolenic acid modulated plasma membrane 
fatty acid composition and the glucagon-stimulated adenylate cyclase activity in rat liver. Chicken hepatocytes with mono fatty acid-enriched plasma membrane established in the present study may be efficiently provided as an available tool to understand the inclusion of hepatic membrane function in the lipid metabolism.

\section{References}

1) An BK, Tanaka K, Ohtani S. Effects of various $n-3 /$ $n-6$ fatty acid ratios in diet on lipid metabolism in growing chicks. Animal Science and Technology, 66 : 830-840. 1995.

2) Belsham GJ, Denton RM, Tanner MJA. Use of a novel rapid preparation of fat-cell plasma membranes employing Percoll to investigate the effects of insulin and adrenaline on membrane protein phosphorylation within intact fat-cells. The Biochemical Journal, 192 : 457-467. 1980.

3) Cheema SK, Clandinin MT. Diet fat alters expression of genes for enzymes of lipogenesis in lean and obese mice. Biochimica et Biophysica Acta, 1299 : 284-288. 1996.

4) Clamp AG, Ladha S, Clark DC, Grimble RF, Lund EK. The influence of dietary lipids on the composition and membrane fluidity of rat hepatocyte plasma membrane. Lipids, 32 : 179-184. 1997.

5) Field CJ, Ryan EA, Thomson ABR, Clandinin MT. Diet fat composition alters membrane phospholipid composition, insulin binding, and glucose metabolism in adipocytes from control and diabetic animals.

The Journal of Biological Chemistry, 265:1114311150. 1990.

6) Fleischer S, Rouser G, Fleischer B, Casu A, Kritchevsky G. Lipid composition of mitochondria from bovine heart, liver, and kidney. Journal of Lipid Research, $8:$ 170-180. 1967.

7) Folch J, Lees M, Sloane Stanley GH. A simple method for the isolation and purification of total lipides from animal tissues. The Journal of Biological Chemistry, $226: 497-509.1957$.

8) Hamm MW, Sekowski A, Ephrat R. Dietary fat ratios and liver plasma membrane lipid composition. Lipids, 23 : 829-833. 1988.

9) Iritani N, Fukuda $H$. Polyunsaturated fatty acidmediated suppression of insulin-dependent gene ex- pression of lipogenic enzymes in rat liver. Journal of Nutritional Science and Vitaminology, 41 : 207-216. 1995.

10) Koumanov KS, Momchilova Pankova AB, Wang SR, Infante R. Membrane phospholipid composition, fluidity and phospholipase A-2 activity of human hepatpma cell linc HepG-2. The International Journal of Biochemistry, 22 : 1453-1455. 1990.

11) Morson LA, Clandinin MT. Diets varying in linoleic and linolenic acid content alter liver plasma membrane lipid composition and glucagon-stimulated adenylate cyclase activity. The Journal of Nutrition, $116: 2355-2362.1986$

12) Schwartz RS, Abraham S. Effect of dietary polyunsaturated fatty acids on the activity and content of fatty acid synthetase in mouse liver. Biochimica et Biophysica Acta, $711: 316-326.1982$.

13) Seglen PO. Preparation of rat liver cells. Experimental Cell Research, 82 : 391-398. 1973.

14) Sipos JC, Ackman RG. Automated and rapid quantitative analysis of lipids with chromarods. Journal of Chromatographic Science, 16: 443-447. 1978.

15) Statistical Analysis System, SAS User's guide : statistics (SAS institute Inc., cd.). Cary, NC 1982.

16) Strum-Odin R, Adkins-Finke B, Blake WL, Phinney SD, Clarke SD. Modification of fatty acid composition of membrane phospholipid in hepatocyte monolayer with $n-3, n-6$ and $n-9$ fatty acids and its relationship to triacylglycerol production. Biochimica et Biophysica Acta, 921 : 378-391. 1987.

17) Suárez A, Ramírez MDC, Faus MJ, Gil A. Dietary long-chain polyunsaturated fatty acids influence tissue fatty acid composition in rats at weaning. The Journal of Nutrition, $126: 887-897.1996$.

18) Tarlow DM, Watkins PA, Reed RE, Miller RS, Zwergel EE, Lane MD. Lipogenesis and the synthesis and secretion of very lowdensity lipoprotein by avian liver cells in nonproliferating monolayer culture. The Journal of Cell Biology, 73: 332-353. 1977.

19) Thi-Dinh KLK, Demarne $Y$, Nicolas C, Lhuillery $C$. Effect of dietary fat on phospholipid class distribution and fatty acid composition in rat fat cell plasma membrane. Lipids, 25 : 278-283. 1990.

20) Toussant MJ, Wilson MD, Clarke SD. Coordinate suppression of liver acetyl-CoA carboxylase and fatty acid synthetase by polyunsaturated fat. The Journal of Nutrition, $111: 146-153.1981$. 